\title{
LUCRECIA Y TARQUINO O EL CONFLICTO ENTRE EL FIN Y LOS MEDIOS
}

\author{
Suele llamarse virtud al poder o facultad \\ inherente a una persona para conseguir un \\ fin cualquiera propuesto. \\ Juan Ginís de Sejúluhad \\ Malos medios dan mal fin, \\ esto dice la experiencia: \\ que la dicha la dan sólo \\ la virtud y la prudencia. \\ At.eLUYA, SIGLO XVII ${ }^{\mathrm{t}}$
}

1. En la introducción de su edición crítica de Lucrecia y Tarquino de Francisco de Rojas Zorrilla ${ }^{2}$, Raymond R. MacCurdy, prácticamente el único investigador que ha estudiado la obra, cree ver en la violación propiamente dicha de la heroína y en el subsiguiente suicidio, el núcleo de la obra, en torno al cual giran, como asuntos secundarios subordinados (o subplots), algunos temas gratos al Barroco: la cuestión ontológico-metafísica de la apariencia y la sustancia (el desengaño), el vanitas vanitatum del Eclesiastés bíblico, el de contemptu mundi y el honor. Víctima tal vez de ciertos prejuicios y tópicos relativos al Barroco en general y a la temática barroca en particular, considera que, en esta pieza, que además de ser barroca es calderoniana (o lopesca, según algunos ${ }^{3}$ ), todas las

1 En Antonina Rodrigo, "Las aleluyas, precursoras de los cómics", $\mathrm{CuH}$, 1988, núm. 462, p. 137.

2 The University of New Mexico Press, Albuquerque, 1963, pp. 1-39. Cito siempre de esta edición.

${ }^{3}$ Véase Joaquín de Entrambasaguas y Manuel Fernández Nieto, "El teatro en el siglo XVII", en Historia de la literatura española, Madrid, 1982, t. 2, p. 677. 
cuestiones políticas que surgen y se desarrollan en el enfrentamiento implícito o explícito entre Tarquino (o ambos Tarquinos) y los súbditos (que tales son todos los demás personajes), es asunto secundario que en algunos momentos anticipa e ilustra "alegóricamente" el tema absolutamente central del rapto.

Esta última sugerencia del estudioso norteamericano, referida al asalto y caída de Ardea como alegoría anticipadora del ataque y destrucción del honor de Lucrecia ${ }^{4}$, es quizá su más sugestiva intuición, aunque no me parece que haya sido convenientemente aprovechada para una correcta interpretación del drama. Lo mismo cabe decir de la tendencia a explicar algunos fenómenos mediante conceptos adquiridos que no siempre casan necesariamente con el caso particular tratado. Así, la subordinación del tema político queda confirmada con el hecho de que el teatro barroco "suele abrirse con temas secundarios" 5 , mientras que la alegoría o el contraste, este último definido como "meollo estético de la obra" 6 , son vistos como rasgos formales, "típicos" y previsibles en toda obra barroca, sin que se justifiquen como producto necesario de la idea que informa el drama. Pese al indiscutible mérito de la labor del profesor MacCurdy, creo que otros postulados de su estudio merecen una profunda revisión o por lo menos un reajuste: lo que él llama insistentemente la "ironía de la obra" y la relación de subordinación o dependencia de Lucrecia y Tarquino de Rojas con respecto al tratado teórico-político de Virgilio Malvezzi, Tarquino il Superbo, la cual, de ser como sostiene MacCurdy, más bien demostraría la prevalencia absoluta del tema político sobre el tema en verdad secundario de la violación en la obra española.

Lucrecia y Tarquino consiste en una larga y reiterada disquisición sobre la moral práctica en el triple e inescindible ámbito de lo individual, social y político, con el fin de definir y legitimar racionalmente una normativa de conducta. El tema, aun siendo único, se desarrolla en tres esferas de igual entidad e importancia, que quedan como inscritas la una dentro de la otra. Quizá no sea casual que, a diferencia de otras Lucrecias, y de manera si-

${ }^{4}$ Como recuerda el mismo MacCurdy, la imagen de la muralla referida al honor de una mujer, es lugar común de la época. NiCOlás Fernández de Moratín, en efecto, utilizará en su Lucrecia la misma alegoría: "Temblando vengo,/ Y no es de miedo, Mevio, te aseguro,/ Pues no temiere el asaltar el muro/ De horribles enemigos coronado" III, esc. 4, Madrid, 1944, p. 110.

${ }^{5}$ Op. cit., p. 15.

${ }^{6}$ Ibid., p. 26. 
milar a algunas representaciones plásticas de la leyenda ${ }^{7}$, Rojas haya puesto en el título el nombre del príncipe y del súbdito, como indicando que el drama ético, centrado en la sexualidad y el amor, es inseparable de las condiciones o "circunstancias" sociales del individuo, al propio tiempo persona física y persona jurídica ${ }^{8}$.

No hay, pues, un tema subordinado a otro, sino tres aspectos diversos del mismo, sobre los que alternativamente se hace luz, según la perspectiva adoptada en los diversos momentos del drama. Todo lo cual no es menos "barroco" que lo señalado por MacCurdy, pues, como es sabido, la época une a la preocupación ontológico-metafísica (la de cierto Quevedo, para entendernos), la continua y casi obsesiva reflexión política y moralista, en el plano teórico-doctrinal del pensamiento político por un lado, y en el del análisis psicológico y de la conducta, por el otro.

Como lo que importa no es el episodio dramático de la violación sino el establecimiento de una normativa conductual, nada tiene de sorprendente que prevalezcan la sentencia, el contraste y la alegoría; la primera para dar forma lapidaria a los conceptos y cristalizar en decálogo laico la normativa elaborada racionalmente por el individuo; el contraste para que, de la aproximación y contacto de polos opuestos, broten las verdades con frecuencia paradójicas a modo de descargas o "chispas" mentales; la alegoría para dar contornos fijos y calidad plástica -o, como dice Cassirer", para transformar en "símbolo visible" - el pensamiento mismo, de otro modo destinado a disolverse en su va-

${ }^{7}$ Así las pinturas de Tiziano, Gentileschi, Biliverti. En pleno Renacimiento, se tiende a centrar el cuadro en la figura de Lucrecia, mientras que en el siglo XVII, aparte de Tiepolo, prevalece la escena del suicidio y del juramento de Bruto con los demás republicanos.

${ }^{8}$ Para un estudio del tratamiento artísticò del tema en Europa, véanse especialmente: IAN DonaldSon, The rapes of Lucretia, Clarendon, Oxford, 1982 y H. Galinsky, Der Lucretia-Stoff in der Welttiteratur, Priebatsch, Breslau, 1932. Por lo que se refiere a España, existen, que yo sepa, los siguientes trabajos: H. Petriconi, "El tema de Lucrecia y Virginia", Clavileño, 8 (1951), 1-5; J. Gillet, "Lucrecia-Necia”, HR, 15 (1947), 120-136; Raymond R. MaCCURDY, "On the uses of the rape of Lucretia", en Estudios literarios de hispanistas norteamericanos dedicados a Helmut Hatzfeld, Hispam, Barcelona, 1974, pp. 297-308; y mis “Lucrècia, de Joan Ramis i Ramis”, en Miscel. lània d'homenatge a Enric Moreu-Rey, Barcelona, 1988, pp. 335-370, y "La tragedia neoclásica española y el ideario de la Revolución francesa", en L. BusQuets (ed.), Cultura hispánica y Revolución francesa, Roma, 1990.

${ }^{9}$ Ernst Cassirer, Individuo y cosmos en la filosofía del Renacimiento, Buenos Aires, 1951, pp. 101-102. 
guedad abstracta. La alegoría anticipadora que MacCurdy cree ver en el relato de la destrucción e incendio de Ardea, sin duda correcta, no demuestra, como él sostiene, que ese tema esté subordinado o apunte exclusivamente al asunto central de la violación, sino que ambos son dos caras de una misma realidad: la realización y conservación de un solo Yo, a la vez privado, colectivo y político.

2. Lucrecia y Tarquino es el drama de la problemática adecuación de los medios a los fines. Todos los personajes, en efecto, se proponen un fin dictado por la necesidad o el deseo, o sea, por la conveniencia $^{10}$. Como tendremos ocasión de ver, a menudo -inconscientemente, fruto de un pragmatismo diríase innato- hacen de la necesidad virtud, es decir, hacen coincidir la necesidad con el deseo: se hacen la ilusión de desear lo que les es impuesto.

Como persona individual, Lucrecia aspira, dice, a la felicidad. Dicha felicidad coincide con la práctica de la virtud, que vemos pronto identificarse con la honestidad. En un momento dado, se habla de honestidad con el sentido de inocencia, que cabría imaginar como desinteresada adherencia al Bien ${ }^{11}$, pero advertimos de inmediato que ésta se confunde con el casto de los versos citados (en la n. 11). Lucrecia da a la honestidad el significado de pureza sexual. Por su condición de mujer casada, dicha "virtud' trasciende lo estrictamente personal y adquire una implicación social: la honestidad significa fidelidad al esposo. En relación con éste, Lucrecia hace de la fidelidad y también de la obediencia y sumisión incondicionales al esposo, su ideal moral. El hecho de que dicha sujeción sea libre y resultado del amor, como insiste Rojas, no quita que el ideal humano de Lucrecia sea la felicidad en el amor institucionalizado del matrimonio, con todos los deberes y constricciones a que le obliga el sistema ${ }^{12}$.

Si en el ámbito de lo social-familiar (el pequeño estado) bas-

10 Cf. Virgilio Malvezzi: "L'interesse comincia dal sublime concavo lunare e penetra anche nelle basse capanne degli umili pastori. Egli nacque con l'universo per mantenere e per distruggere l'universo. Egli è l'etica del mondo, penetrata anche nelle parti solide. Non solo l'uomo vorrebbe dominar l'uomo, ma l'elemento gli elementi, ed allora che uno averà sortito il suo intento, lo sortirà anche l'altro, perché finisca il mondo con quello interesse nel quale comiciò" (Discorsi sopra Cornelio Tacito, Bolonia, 1622, p. 21).

11 " $\mathrm{Si}$ el hado fatai permite/que el pecho casto derrame/líquido rubí inocente,/esa inocencia le baste" (vv. 571-574). 
tan la fidelidad y la obediencia, en el de la comunidad humana, de "los otros", Lucrecia aspira como fin supremo a la honra (es decir, el buen nombre, la reputación), a la salvaguardia del propio honor y, como le corresponde institucionalmente, a la del honor de su esposo. Ello no implica que Lucrecia aspire a una respetabilidad hipócrita13. Sus sentimientos "virtuosos" son auténticos y sinceros, de acuerdo con una visión del honor que encontramos también, significativamente, en Saavedra Fajardo: que no basta " a mantener la reputación, si falta la virtud y valor propio, como no hacen estimado al espejo los adornos exteriores, sino su calidad intrínseca" 14 . Sin embargo, ambos fines no coinciden necesariamente entre sí, como tampoco coinciden los medios para alcanzarlos; lo que pudiera satisfacer la honestidad individual, podría no resultar satisfactorio o suficiente para salvaguardar esos otros fines que trascienden la esfera de lo personal. Como súbdita, la máxima aspiración de Lucrecia es la incondicional obediencia al soberano. Siendo el Estado la "familia mayor", es más fácil que coincidan entre sí los fines de los distintos ámbitos de lo social, que los fines sociales con los individuales. Como se echa de ver, Lucrecia hace suyo el ideal de perfección que le impone la sociedad de su tiempo.

Tarquino, en su calidad de monarca, incluye dos personas netamente separadas, como se admite teóricamente a partir de Maquiavelo: una privada y otra pública. Como hombre, se halla inserto en un orden moral que más o menos vagamente se atiene a los principios de una ética trascendente; como político, debe seguir lo que le impone la ciencia política o razón de Estado, que puede estar en contradicción, y suele estarlo, a partir también de Maquiavelo, con las leyes morales universalmente aceptadas y el derecho, aunque en teoría los antimaquiavelistas de cuño cristiano y católico pretendan subordinar, en verdad con poco convencimiento, la razón de Estado a la virtud moral o a la virtud cristiana. En cuanto príncipe, el fin de Tarquino (de ambos Tarquinos) es la consecución y mantenimiento del poder; como hombre,

12 Sobre el concepto "revolucionario" de la libertad amorosa en Rojas, Julio RodRíguez-PuÉRtolas precisa que no se trata de una invención de este autor, "Alienación y realidad en Rojas Zorrilla", en De la Edad Media a la edad conflictiva, Gredos, Madrid, 1972, p. 355, n. 44.

${ }^{13}$ Lo reconocen los demás personajes: "Aquí no hay comedia, Acronte;/ virtud, sî' (vv. 1141-1142).

14 Diego SaAvedra Fajardo, Idea de un príncipe político-cristiano, EspasaCalpe, Madrid, 1969, t. 2, p. 58. 
es la satisfacción de un deseo, dictado menos por la lujuria que por la ambición. No debe olvidarse, en efecto, que Tarquino se enamora tanto de la belleza de Lucrecia como de su extraordinaria honestidad y prudencia, es decir, queda prendado de lo que hay en ella de excepcional y de grande; la califica repetidamente de "divina"; la llama "cielo" y "sol". Cuando la ha poseído, dice "toqué el sol, ofendí al cielo"' (v. 1999). Tarquino hace de su ideal humano la potencia, la grandeza, la totalidad, porque, como dice Saavedra Fajardo, "un ánimo grande apetece lo más alto"' 15 .

También Tarquino manifiesta en sus fines una perfecta adherencia a las funciones políticas de su tiempo y a lo que, en la práctica, se ha vuelto el ejercicio del poder indivisible y absoluto. No menos en cuanto ser humano, pues responde al cliché elaborado en su época del hombre fuera de lo común, grande en el bien y en el mal, en correspondencia con su destino y condición de príncipe, ya que, según recuerda Meinecke, "sin el instinto de potencia que poseen los hombres enérgicos no sería posible ni el nacimiento del Estado ni la potencia que necesita para su mantenimiento"16. Hombre y príncipe se hallan tan inextricablemente unidos que es difícil establecer cualquier deslinde.

Colatino tiene también sus fines diferenciados con arreglo al triple plano en que se desenvuelve su persona jurídica y humana. Como individuo, aspira a la ostentación y al halago. Por encima de todo, desea que los demás consideren a su esposa la más bella y honorable de las mujeres, y a él, el más dichoso y envidiable de los mortales. Su mira (su punto débil) es la vanidad personal, en el plano privado y también público, pues anhela asimismo ser reconocido como perfecto súbdito y soldado. Si en el ámbito privado-familiar para él la felicidad reside en el amor, y la fidelidad en el honor, en el ámbito político, estima que el deber consiste en la ciega obediencia ${ }^{17}$. Sus fines públicos se acomodan a los valores/constricciones que le impone la sociedad en que se halla inserto; sus fines privados, a las debilidades y flaquezas de su naturaleza humana. Ya veremos que la vanidad, más que un vicio

${ }^{15}$ Ibid., p. 65 .

${ }^{16}$ Federico Meinecke, L'idea della ragion di Stato nella storia moderna, Vallecchi, Firenze, 1942, p. 19.

${ }^{17}$ Sobre lo que se ha dado en llamar "religión de la obediencia", véase José Antonio Maravall, Teatro y literatura en la sociedad barroca, Seminarios y Ediciones, Madrid, 1972, p. 78, y Estado moderno y mentalidad social, Alianza, Madrid, 1986, t. 1, pp. 297 ss. 
moralmente reprochable, es un escollo, un impedimento.

Los súbditos - ora el senado, ora los ardeatinos o los gabiosaspiran indistinta y genéricamente a la autonomía y a la libertad. También en ellos se hacen patentes las aspiraciones libertarias que subyacen al absolutismo real, amenazando la unidad nacional y el sistema monárquico-señorial desde sus albores. Ellos reivindican para sí, de forma entre incoherente y larvada, el derecho del pueblo a participar en la gestión del Estado, así como el derecho a la oposición y a la resistencia. De hecho, sin embargo, tanto los ardeatinos como los gabios sienten el peso de su impotencia política y buscan seguridad, protección y guía: alguien que al cabo los gobierne y dirija.

Al Bruto de la obra de Rojas le queda, de su ilustre antecedente histórico-legendario, la reivindicación formal, y vaga, de la libertad. Si allí era amor patrio y aspiración colectiva a la libertad, es aquí tan sólo alegoría de una abstracción. MacCurdy le llama el raisonneur, pero en mi opinión este apelativo es más propio de Lucrecia que de Bruto. Este es la lucidez mental, la Mente, el dominio del complejo mecanismo de las causas y de los efectos. A diferencia de Don Quijote, Bruto, para comprender el mundo, no necesita "topar con" la realidad: pre-ve en forma de pre-ciencia innata. Como indica su nombre en una antítesis ontológica tan del gusto de su época (los hombres/los brutos) - que es el fundamento y la necesidad interior del contraste-, Bruto es la Razón que los estultos toman por locura. Pero es menos la razón "raciocinante" que se ocupa de las acciones singulares, de lo contingente, que la Razón-Sabiduría, entidad superior de la que aquélla deriva.y cuyo objeto son las cosas universales y perpetuas $^{18}$. Su fin es ver, conocer, codificar el saber y comunicarlo. Bruto es la luz de la Razón con la que los demás personajes, si quieren, pueden iluminar su circunstancia.

Pericles aspira a la seguridad a cualquier precio. Es la expresión del hombre medio, de ese vulgo nacido para obedecer del que hablan Gracián, Saavedra Fajardo y la mayoría de moralistas y tratadistas políticos del momento, sin necesidad de acudir necesariamente a Malvezzi.

Julia, por último, representa el descontento estamental. Su as-

${ }^{18}$ Cf. SaAvedra Fajardo: “. . . la experiencia, madre de la prudencia, con quien se afirma la sabiduría. Tiene ésta por objeto las cosas universales y perpetuas, aquélla las acciones singulares; la una se alcanza con la especulación y estudio; la otra, que es hábito de la razón, con el conocimiento de lo bueno o malo, y con el uso y ejercicio" (op. cit., p. 44). 
piración es ir a más, ascender en la escala social. Que, como es sabido, es el anhelo y aspiración colectivos de los hombres desde el Renacimiento, exasperados en el período barroco.

3. Para la realización de sus fines, el hombre tiene que contar con la ocasión o circunstancia -individual, social y política- que es su tablero de juego, vagamente vinculado a una mal definida Fortuna.

En la pieza se mencionan los cielos y el hado, casi siempre sinonímicamente. El hado es el conjunto de los signos del zodíaco que Malvezzi veía como determinantes de la condición de los hombres y sobre todo de la distinción entre aquellos que nacieron para mandar y los que nacieron para obedecer. En algunas ocasiones (al final, cuando Tarquino habla de haber ofendido al cielo y Lucrecia apela a los dioses de la hospitalidad), se dibuja más allá del hado, no tanto un Ser Supremo que maneja la rueda de la fortuna, como una presencia, un testigo - la idea del Bien o de la Justicia - que, sin embargo, aparecen desgajados de la realidad y vicisitud de la pieza.

El hombre, lanzado al mundo, dejado de la mano de Dios e imantado por un hado que, más que determinarlo lo "inclina"'19, tiene que habérselas con la propia inclinación y con sus propios límites, esto es, con la circunstancia de su ser y con el infinito juego combinatorio de las circunstancias. Para afrontar el mundo, esta realidad varia y móvil rigurosamente trabada por una lógica interior, no basta la voluntad: es preciso conocer a fondo el tablero de juego, estudiar los fines, calcular y organizar los medios. El mundo, por otra parte, no es una abstracción: son "los otros", esos lobos temibles de los que es posible defenderse si se conocen las leyes que regulan su comportamiento. La virtú maquiavélica se llama ahora, como es sabido, prudencia, como aquélla, desprovista de todo valor moral trascendente, aunque no falte quien aconseje la práctica de la virtud (cristiana) para granjearse el favor de las estrellas y de Aquel que maneja las estrellas (la gracia). En el combate entre virtù y fortuna - entre el Yo y la circunstanciapara que la voluntad sea eficaz (y no hay más sabiduría que la que desemboca en la eficacia) ${ }^{20}$, debe ir guiada por la sabia pru-

19 "Yo, que por ley del hado/nací a violencias tales inclinado" (vv. 4344). Cf. SaAvedra Fajardo: "Alguna fuerza oculta parece que si no impele, mueve nuestra voluntad y la inclina más a uno que a otro", op. cit., p. 231).

${ }^{20}$ Lo dice también un personaje de la obra que nos ocupa: "Tú piensas/ bizarramente si así/ lo ejecutas"' (vv. 1632-1634). 
dencia, que correctamente mira (y sólo entonces ve) y correctamente actúa. El mundo da sus avisos a quien sabe acercarse a él con los medios apropiados. No hay peor culpa que negarse a ver lo que está a la vista de todos, aunque envuelto en las apariencias engañosas, que no son apariencias de lo fenoménico, sino disfraz e hipocresía humanos.

Con la carga de su libertad y responsabilidad a cuestas, el hombre, mientras con la experiencia propia y ajena perfecciona el instrumento de su razón, puede y debe hacerse a sí mismo. En esa su realización en el mundo, vive una especie de esquizofrenia, amoldando su conducta, ora a la moral cristiana, igual para todos los hombres que deseen salvar su alma, ora a una moral circunstanciada o de estrategia, distinta según la función y el puesto que ocupe en la realidad social. Como el hombre, el Estado (el hombre es como un Estado, y viceversa) tiene en sus manos los medios para su realización y mantenimiento, o para su ruina, según actúe de acuerdo con la razón, o prudencia, o en contradicción con ella. Imperativo racional y relativismo ético constituyen a la vez las coordinadas del obrar humano y del código "moral" que lo reglamenta.

Lucrecia es la personificación de la prudencia, valga la rima, que desmiente con mayor eficacia aquel malicioso e irreverente Lucrecia-necia que estudiara Gillet en $1947^{21}$. Ella es la sindéresis o juicio, que, al decir de Gracián, es el "trono de la prudencia" 22 . Una frialdad "raciocinante" y una entereza entre férrea y plúmbea distinguen su personalidad y su figura, como para rebatir el tópico de la volubilidad y fragilidad de la mujer que se infiltra en pleno Siglo de las Luces (piénsese en el Cosi fan tutte). No será ella quien caiga en la trampa de considerar a las estrellas responsables del acaecer humano. Lucrecia conoce a fondo su tablero de juego. Contemplando los datos sueltos que le ofrecen los comportamientos y situaciones particulares (la experiencia), es capaz de deducir leyes generales sobre la naturaleza del ser humano (el deseo) y sobre el hombre en sociedad (la murmuración, la envidia), y de extraer de ellas una normativa de comportamiento. Nadie como ella estudia la esencia de su fin y calcula los medios que la tienen que llevar o alejar de él. Prevé de las causas las consecuencias; ve que para la salvaguardia de su reputación es necesario no dar pábulo a la murmuración, y que para defen-

${ }^{21}$ Art. cit.

22 Baltasar Gracián, El héroe. El discreto, Atlas, Madrid, 1969, p. 13. 
der su honestidad ( = castidad/honor) es preciso no dar ocasión al deseo. Lucrecia conoce la naturaleza "personal" y peligrosa del príncipe ( = fuego) ${ }^{23}$ y su naturaleza jurídica; sabe que a ella le toca obedecer y que, estando sujeta al régimen jurídico del honor, no es posible defenderse de una posible ofensa del rey ${ }^{24}$. De ello saca su norma de conducta, basada en aquella "prudente difidencia" de que habla Saavedra Fajardo 25 , que es el mandamiento prudencialista de la época: guardarse. En contra de la opinión de $\mathrm{MacCurdy}{ }^{26}$, considero que su retiro del mundo nada tiene que ver con el espíritu ascético en general ni con el mandamiento católico de evitar el pecado, en particular. Lucrecia no se guarda para no exponerse al pecado, ya que su entereza moral y fortaleza de ánimo la aseguran contra toda tentación del diablo; se guarda de los demás y de la circunstancia. El mundo no es tentación del alma, sino peligro que puede interceptar la realización de uno mismo. La suya no es sapiencia estoica, sino aquella prudencia basada en la experiencia, cuyo objeto, a diferencia de la sabiduría de Bruto, son las acciones singulares y contingentes.

Se diría, pues, que Lucrecia domina su circunstancia de tal modo que está fuera de todo peligro. Como es sabido, el error, la im-prudencia, la comete el marido, lo que hace que el tablero de juego presente de improviso un aspecto inédito, que ella, sin embargo, juzga y examina con la amplitud de miras que le es propia.

¿Por qué, a pesar de tanto raciocinio y prudencia, se verifica la violación temida? Aparentemente, a causa de la violencia de Tarquino y de su propio estado de in-consciencia. Pero mirándolo bien, advertimos que el sistema lógico de Lucrecia presenta algunas deficiencias que bastan para precipitar la acción fuera de los cauces previstos. La primera es creer que la fuerza de la razón y su acción de convencimiento racional son tan eficaces que pueden por sí solos disuadir al tirano de su intento. De no ser así,

23 ، ". . y que es imprudente y ciego/quien mete el fuego en su casa./Fuego los príncipes son" (vv. 1786-1788). MACGuRdy cita otros versos del mismo Rojas: "Que era el rey como la lumbre/Que calentaba de lejos/y desde cerca quemaba"' (op. cit., p. 123).

${ }^{24}$ El mismo MacGurdy recuerda las condiciones histórico-políticas y doctrinales, citando con acierto los trabajos de PFANDL, Cultura y costumbres del pueblo español de los siglos xvi y xvii, Barcelona, 1929, y de AmÉRICo Castro, "Algunas observaciones acerca del concepto del honor en los siglos XVI y XVII", RFE, 3 (1916), 2-50.

25 SaAvedra Fajardo, op. cit., p. 272.

26 Op. cit. 
no se comprende por qué motivo ella, tan aficionada a pasarse las noches en vela (a la "prudente vigilancia"), se acuesta tranquila tras la discusión disuasiva con Tarquino. $\mathrm{Y}$ digo tranquila porque efectivamente se duerme, favoreciendo así la intrusión del príncipe en su aposento y el estupro. En plena violación, Lucrecia, obstinada en su error, trata aún de oponer a la fuerza de Tarquino, la fuerza de la convicción y la razón ${ }^{27}$. Lucrecia confunde el plano intelectual-teórico con el plano práctico-racional. Los demás errores atañen al conocimiento del complejo y contradictorio mecanismo de la psicología humana. No sabe que la honestidad y el bien pueden ser acicate a la deshonestidad y al mal, y que la privación aumenta el deseo ${ }^{28}$. Lucrecia desconoce aquellas verdades "universales y perpetuas sin las cuales la experiencia de poco vale"'29. En el fondo, peca de orgullo intelectual, de un exceso de seguridad en sí misma ${ }^{30}$. Julia le había ya insinuado que su cuadro de referencia presentaba algunos puntos débi$\operatorname{les}^{31}$. Bruto, por ejemplo, que atiende a las verdades "universales", sabe muy bien que cuanto más inalcanzable aparece el objeto del deseo, con tanta mayor intensidad se anhela. La violación es, pues, resultado necesario de una serie de presupuestos errados.

Importa subrayar que Lucrecia es incapaz de imaginar una solución cualquiera fuera de los esquemas que le imponen las convenciones sociales y políticas: el código del honor, los derechos del príncipe, la obediencia incondicional del vasallo. Consumado el delito, contempla de nuevo "racionalmente"' los fines individuales, sociales y políticos que le exige el sistema: la seguridad del marido, el amor indisolublemente unido al honor, porque " no

27 “ . . . resuelta, determinada,/descompuesta y sin aliento,/quejas le propone al viento,/voces a mi fe jurada,/lástima a mi piedad,/respetos a mi grandeza" (vv. 2018-2023).

${ }^{28}$ Es una "verdad"' que los textos de la época repetirán con frecuencia. MacCurdy cita ese verso de Lope: "Porque resistido amor,/con la privación se aumenta" (op. cit., p. 133).

${ }^{29}$ Cf. SaAvedra Fajardo, empresa 29, op. cit., pp. 38-43.

30 Véase SAAVEDRA FAJARDo: "y así, es conveniente que gobierne la prudencia, y que ésta no viva pagada y satisfecha de sí, sino que consulte con la variedad de los accidentes que sobreviven a las cosas, sin asentar por ciertas las futuras, aunque más las haya cautelado el juicio y la diligencia" (ibid., pp. $40-41)$.

31 " Líbrete el cielo de quien/por inclinación murmura;que dél no hay honra segura, aunque ocasión no le den" (vv. 1121-1124). Cf. SAAvedra FAJARDO: "La obligación del príncipe sólo consiste en desear acertar y en procurallo, dejándose advertir y aconsejar, sin soberbia ni presunción" (op. cit., p. 37). 
hay amor donde no hay honra"'32. Para ello predispone los medios adecuados: la pública manifestación del ultraje y la propia muerte, con lo que sustituye a su esposo en la venganza y asegura con ello la reparación formal de la afrenta y el orden establecido $^{33}$. En nuestra Lucrecia, no cabe siquiera mencionar la cuestión moral de la intención y la consecuencia, la incoherencia entre no culpabilidad y castigo. Está claro que su fin primordial no es la virtud, sino la honra, que su preocupación no es el pecado, sino la reputación. En este sentido su comportamiento es perfectamente lógico y coherente ${ }^{34}$, sin que Rojas haya tenido que recurrir a la historia del esclavo, que marca en la leyenda los dos momentos fundamentales del conflicto ético.

Como persona jurídica, Tarquino conoce la esencia del poder y medita los medios prácticos para conseguirlo y mantenerlo, independientemente de toda ley moral (natural o positiva), según es norma y costumbre, aun en el plano doctrinal, a partir de $\mathrm{Ma}$ quiavelo. Las reflexiones o diatribas de Tarquino con su padre o con sus súbditos dan ocasión a Rojas de llevar a las tablas algunas de las cuestiones políticas más manidas de la época, todas ehas de inspiración, o divulgación, maquiavélica: la esencia del Estado, la legitimación del príncipe, la justificación de la violencia, de la simulación y del engaño para la consecución y el mantenimiento del poder, las vanas y consabidas disquisiciones acerca de si es mejor para el monarca ser amado o ser temido para la obtención de sus fines.

Tarquino es el príncipe maquiavélico que conoce el mecanismo psicológico de los hombres - de ese hombre que fundamentalmente es siempre igual a sí mismo- para manipularlos, dominarlos y utilizarlos para sus propios fines, que, no lo olvidemos,

${ }^{32}$ Obligados y ofendidos (citado por ERmanno Caldera, "Solitudine dei personaggi di Rojas", Studi Ispanici, 1, 1962, p. 54). A propósito de la sumisión al sistema, Rodríguez PUÉrtolas observa: "la independencia que Rojas concede a sus heroínas es ficticia, pues se trata, en realidad, del sometimiento de las mismas al rígido concepto del honor"' (op. cit., p. 355).

${ }^{33}$ Se ha insistido mucho en el supuesto feminismo de Rojas y en el hecho de que es frecuente que en sus obras la mujer sustituya al hombre para la venganza (véase MACCuRdy, op. cit., pp. 119-120). CaLdera reduce justamente el significado "revolucionario" de esta solución en otras piezas de Rojas, justificándola por otros motivos; aquí se trata de la incapacidad absoluta de Colatino en los términos expuestos (art. cit., pp. 40 ss.)

${ }^{34}$ MaCCuRdy observa que sólo en esta obra la violación se verifica con Lucrecia inconsciente. En cuanto a MALVEzzI, es evidente el diferente concepto que tiene de este personaje (op. cit., p. 32, n. 20). 
son los fines de ese ente político soberano que llamamos Estado. La propia experiencia y la experiencia acumulada que le trasmite la historia, esto es, el conocimiento de aquellas "verdades universales y perpetuas" que Lucrecia ignoraba ${ }^{35}$, le enseñan que para dichos fines es preciso servirse de la fuerza y de los recursos de la razón de Estado; sabe (él o su padre, no importa), que la figura del monarca se refuerza dándole lustre y aureola divina ${ }^{36}$; conoce la importancia de disponer de un ejército regular formado por hombres fieles y devotos a ultranza, a los que es necesario halagar y favorecer; sabe que los hombres son sensibles a la adulación y que la necesidad o el deseo los hace vulnerables al engaño; sabe -y repite casi las palabras de Maquiavelo- que los hombres se olvidan de la violencia si el príncipe sale victorioso de la empresa, y que siendo la debilidad el peor enemigo del príncipe, es mejor ser admirado por temido que despreciado por amado.

Armado de tanta sabiduría general y práctica, Tarquino emplea los medios adecuados para conseguir su fin: como animal al acecho en espera de la ocasión propicia -imagen grata a $\mathrm{Ma-}$ quiavelo-, coge al vuelo la necesidad de los gabios de ser dirigidos y protegidos para apoderarse del poder, acudiendo a los medios "legítimos" que le ofrece la razón de Estado y explotando la propensión de los hombres a juzgar favorables los sucesos adversos bajo la presión de la necesidad o el deseo.

Como persona privada, Tarquino sabe que ésta afecta tan sólo a su conciencia y que ante Lucrecia no existe sino su persona jurídica. Tarquino estudia las causas y los efectos: que Lucrecia puede ser sensible a sus halagos y promesas, y que es posible vencer su voluntad con el engaño o su cuerpo con la violencia. Considera el obstáculo representado por Colatino, pero, buen conocedor del ánimo humano, maneja con eficacia el resorte de su amor propio y de su incondicional obediencia. Es difícil discernir si en el éxito de su empresa ha podido más la simulación (fingirse convencido por las razones de Lucrecia) o la fuerza. En cualquier caso, la primera ha hecho posible la segunda, y a Tarquino no nos

35 “"Entendióle; yo imagino/la misma agudeza en ti./Sexto. Son tus palabras en mí/un oráculo divino;/y lo que has dicho es bastante/para entender y saber..." (vv. 831-836).

36 “ . . que ilustra más mi persona/la sangre de esos tiranos/que está tiñendo mis manos,/que el oro de mi corona"' (vv. 153-156); "Muévaos impulso divino;/todos mi nombre aclamad"' (vv. 249-250). Cf. SaAvedra FajarDo: "Con ellos procure vuestra alteza ilustrar su real persona" (op. cit., p. 63). Las cursivas son mías. 
queda sino felicitarlo por la perfección de sus planes y la resolución de su intento.

Diríase que lo único que Tarquino no ha previsto, pues el conflicto aparece en un segundo momento de forma totalmente inesperada, es que si en lo político los fines justifican los medios autónomamente de toda consideración ético-trascendente, no vale lo mismo en lo privado, donde no es posible eludir la conciencia. Conciencia que, naturalmente, no responde de sus actos ante sí misma, sino a una ley exterior, a los "cielos", al juicio divino: “toqué el sol, ofendí al cielo" . A diferencia de los demás Tarquinos, y significativamente al igual que el Tarquino de Shakespeare, el príncipe de Rojas siente remordimientos de conciencia, por lo que se convierte en una especie de pecador arrepentido que apela a la justicia divina contra sí mismo, confirmando lo que decía Saavedra Fajardo, que "en sí mismo trae venganza quien es enemigo de Dios" 37 . Que es como decir, y como en efecto se dice frecuentemente en la escena española, que "nadie ha de juzgar/a los reyes, sino Dios"'38.

Pero mirándolo bien, nada en Tarquino es dejado al azar o a la improvisación; no hay nada que no haya sido previsto y calculado, incluido el error: "tengo/determinación resuelta/de faltar a ser quien soy', (vv. 1587-1589).

Tarquino se está sirviendo de la fórmula "yo sé quién soy", de la que se ha ocupado con gran penetración José A. Maravall. Éste sostiene que "junto con el reconocimiento del albedrío, no político o social", dicha fórmula se refiere a la "correlación entre lo que uno va a realizar y lo que le corresponde socialmente y los demás esperan de él"'39. Según ello, Tarquino decidiría faltar a ser lo que debiera ser o como príncipe maquiavélico o como príncipe cristiano (no menos maquiavélico, como es sabido). Me parece, sin embargo, que el ego sum qui sum tiene aquí un doble significado en correspondencia con la esquizofrenia arriba apuntada. El 'error' de Tarquino es, por un lado, una insensatez moral que afecta su conciencia de cristiano -o de príncipe cristiano, que es lo mismo- de la que, por tanto, no tiene por qué dar cuenta a sus súbditos; por el otro es una insensatez política en cuanto representa un atentado a la razón de Estado y al mantenimiento del poder. Doble ruinosa consecuencia a la que parecen aludir el

${ }^{37}$ Ibid., p. 21.

38 Calderón, Saber del mal y del bien (jorn. I, esc. 8), en Obras, Aguilar, Madrid, 1944, p. 22.

39 Teatro y literatura..., pp. 97 y 103 , respectivamente. 
“"estar fuera de sî", el "ser otro" y sobre todo el "estoy perdido", pronunciados por Tarquino en el tercer acto.

Desde el momento, sin embargo, que la salvación de su alma queda asegurada con el arrepentimiento, parece evidente que el " "estoy perdido" se refiere a las consecuencias que Tarquino prevé de su imprudencia, pues aun siendo señor de cuanto pertenece a sus vasallos, según admiten los propios súbditos, con la consabida exclusión del alma o conciencia ${ }^{40}$, los tratados políticos de la época, empezando por Il principe, aconsejan, a título de prudencia, no tocar las haciendas y mujeres de los mismos, "bienes" unas y otras (lo dice el mismo Colatino), porque ello es causa de resentimiento e induce a la resistencia.

El único error intelectual de Tarquino podría ser, a primera vista, el no ver la verdadera naturaleza de Bruto, creer que es absolutamente inofensivo, caer en la trampa de su disfraz. Pero tal como Rojas ha tratado la figura del cabecilla rebelde, encarnación del espíritu patriótico en obras de cuño liberal - que es el mayor peligro que el príncipe prudente debiera erradicar de su entorno-, la lucidez de Bruto no representa peligro alguno, en cuanto no pasa de representar la transgresión autorizada e institucionalizada del loco-cuerdo, del bufón o fool tradicionales, cuyas verdades, pronunciadas al margen de lo social, no atentan para nada contra la estabilidad del sistema ${ }^{41}$.

De todo ello se desprende, pues, que la im-prudencia de Tarquino es menos manifestación de irracionalidad que de voluntad de potencia (y tal es el significado que tiene en la pieza el apetito sexual, que no amor o pasión, del Tirano): audacia temeraria que, como quedará demostrado, no va a comprometer seria e irreversiblemente su posición.

Por lo tanto, Tarquino representa la razón y la prudencia en grado sumo, así como en grado sumo, en el bien o en el mal, encarna la libertad, la determinación y la voluntad. En el fondo, posee las cualidades de los hombres grandes nacidos para el mando de que habla Malvezzi, sujetos al influjo de las estrellas "im-

40 Aunque Pericles encarne el reaccionarismo extremo, no es menos reaccionaria la opinión general que sale de la obra (cf. MACGuRdy, op. cit., p. 133).

41 Contra la opinión de MacCurdy, creo, pues, que Bruto es sustancialmente el gracioso (véase MAcCurdy, op. cit., p. 115). Recordemos, por otra parte, que MESONERo RoMANos elogiaba "la epigramática expresión de sus [de Rojas] graciosos" ("Teatro de Roxas", en Seminario Pintoresco español, Madrid, 1851 , t. 16, p. 370). 
perantes" 42. Al igual que ellos, posee grandes virtudes y grandes vicios, tales como la soberbia, la crueldad y la lujuria, vicios/virtudes que incluso los tacitistas exaltaron en Tiberio como indicio y expresión de potencia: "una gran libidine è molte volte segno d'un grande intellecto' '; "in un principe, fra i difetti, è de' i minori la lussuria" 43. Tarquino es "el ánimo grande que apetece lo más alto", el león astuto, fiero y cruel, "símbolo de la vigilancia", destinado "por naturaleza" a ser rey de los animales ${ }^{44}$. Y para atenuar su "pecado", al que como hombre es proclive como los demás mortales, Rojas ya nos ha dicho que las estrellas lo inclinaban algo hacia el mal.

En cuanto a los súbditos, es difícil no hallar quien, de un modo u otro, no haya cometido alguna equivocación. El venerable anciano del Senado, pese a la rectitud de su conciencia y a la bondad de su intención, comete tal vez el más grave atentado contra la prudencia. En torno a su figura, como también a la de Bruto, pero en éste vanamente por su posición marginada, giran las reflexiones sobre el valor y la prudencia (en el sentido actual del término), o si se quiere, sobre la audacia y la discreción. El coraje y arrojo del anciano son resultado de un error intelectual: no haber previsto la inutilidad de su acción en aquel momento. No hay época menos heroica que ésta en que se escribe El héroe: "entre estos dos extremos [los desconfiados y los arrojados] se halla el seguro medio de cordura; y consiste en una audacia discreta, muy asistida de la dicha"'45. Dadas las circunstancias, el anciano debía haber actuado con disimulo para obtener en el momento oportuno la realización de su en sí noble deseo. No es preciso acudir necesariamente a Malvezzi y menos aún a Tarquino il Superbo para hallar encomio del gran arte de la simulación, "hija de la astucia y de la paciencia", unánimemente aconsejada por tratadistas políticos y moralistas a príncipes y vasallos ${ }^{46}$ : "chi nasce nella

${ }^{42}$ Davide perseguitato, Bologna, 1634, p. 50.

${ }^{43}$ Virgilio Malvezzi, Considerazioni con occasione d'alcuni luoghi delle vite d'Alcibiade e di Coriolano, Bologna, 1648, p. 73. Meinecke recuerda: "la pleonexia (il piacere della potenza) è accanto alla fame e all'amore, l'istinto umano più potente, più elementare ed efficace" que "ha destato la specie umana alla vita storica" (op. cit., pp. 11-12).

${ }^{44}$ SaAvedra Fajardo, op. cit., pp. 182 ss.

45 Baltasar Gracián, op. cit., pp. 50.

46 Véase Eugenio Garin: "altri, come il Malvezzi, insiste sul dovere di simulare con i potenti, quale mezzo di difesa, limitando il suo problema ai rapporti dell'individuo con il potere esterno tirannico . . . virtù primaria è la pazienza come capacità di adattamento, flessibilità di giunco che seconda alle 
gran scena del mondo dovrebbe sapersi vestire di molti abiti per potere in questa commedia rappresentare diversi personaggi" 47 .

Es lo que hace Bruto, el "sabio prudente", que se viste de loco, disfrazándose incluso el nombre para dar mejor al mundo la apariencia opuesta de lo que es. Pero como ya he dicho, el Bruto de la obra de Rojas es un aborto desde el punto de vista de la acción política. Por eso, a diferencia de los demás Brutos que nos han legado la historia, la literatura y el arte, este Bruto no calla en espera de actuar en el momento oportuno, es decir, al estar seguro de que su acción será eficaz, sino que habla con la esperanza de que los otros iluminen su circunstancia a la luz de su sabiduría; por eso mismo, sus apartes teatrales tienen siempre dos tiempos, el susurro y la repetición de lo susurrado en voz alta con fórmulas del tipo "¿qué dices, Bruto?" y afines en boca de otro personaje; por ello, justo en el momento de la "acción”, el personaje desaparece de escena ${ }^{48}$. Sus verdades son inocuas, sea porque su apelación a la libertad suena como declaración puramente formal y desgajada de toda necesidad lógica, sea porque sus ideas sobre el Estado no atentan sino que más bien fundamentan el sistema absolutista representado por los Tarquinos. La afirmación de que la verdad resulta incómoda al Principado ${ }^{49}$ o de que el súbdito reina en su casa como el príncipe en la suya, son irrelevantes si él mismo puede afirmar "que el cielo/que sujetó las ciudades/a los Tarquinos, no quiso que las almas sujetasen" (vv. 526-528). Con lo cual por un lado legitima la institución monárquica mediante la doctrina del origen divino, y por el otro confirma la tesis de la jurisdicción real sobre las personas y haberes de sus súbditos, no sobre la conciencia de los mismos, que es lo que Lope y todos los dramaturgos de la época vienen repitiendo en favor del poder absoluto. De lo que se deduce que Bruto no representaría un peligro ni aun en el supuesto de que los otros se comportaran según Razón/Bruto, en cuanto no harían sino adherir sus voluntades a las "razonables" necesidades y deseos que les impone el sistema.

De los ardeatinos vencidos cabe decir lo que del noble y vetusto anciano del Senado. Que la resistencia es razonable cuando

percosse, e perciò appunto no si spezza mai" (La Filosofia, Milano, Vallardi, 1947 , t. 2, p. 232).

47 Virgilio Malvezzi, Davide perseguitato, p. 36.

${ }^{48}$ MacCurdy, en efecto, observa el fenómeno, pero no parece encontrarlo significativo (op. cit., p. 28).

49 "porque en todo principado/su verdad [de Bruto] es infelice"' (v. 220). 
es previsible la victoria y es insensata cuando está necesariamente abocada al fracaso. Inútil, por lo demás, resulta acusar al Tirano de traición. El hombre debe contar con el engaño y la simulación, medios legítimos para mantener el principado y tanto más para conseguirlo ${ }^{50}$. El fallo de los gabios reside en no haber visto; peor, habiendo visto, haberse engañado a sí mismos, empelidos por la necesidad y el deseo ${ }^{51}$. El principal error consiste en no saber que la necesidad primigenia de asociarse y las necesidades de los pueblos sometidos son precisamente, las causas que originan al mismo Estado y a la razón de Estado; su segunda equivocación es creer que, otorgado el poder a Tarquino, aquél es aún cosa suya, y que puede hacer y deshacer a su antojo. Será fácil para Tarquino desmontar sus pretensiones por vía lógica. Para ello acude, simplificándola y desposeyéndola de todo fundamento jurídico, a la vieja teoría del pacto y contrato, sosteniendo que los individuos, en el momento mismo en que ceden al monarca la gestión del Estado, le otorgan unos poderes que vinculan a ambas partes ${ }^{52}$. Aunque Tarquino apele formalmente a unos supuestos deberes del rey, cuyo incumplimiento presupone traición y subsiguiente escisión del contrato, de hecho, insistiendo en el carácter libre e irreversible del otorgamiento ${ }^{53}$ y sin mencionar para nada la legitimación legal del monarca con respecto a la ley natu= ral o divina, y tanto menos la soberanía del pueblo implícita en el concepto de poderes, no hace sino legitimar la arbitrariedad y el absolutismo monárquicos, descargando en el pueblo la respon-

${ }^{50}$ Cf. Maravall: "Este arzobispo toledano, Rojas, gran señor, que por extender su poder era capaz de servirse de armas ajenas a toda consideración moral-religiosa, bien podría haber figurado como un personaje de El Príncipe. La práctica del engaño no sólo era propia de un Fernando el Católico, de un Luis XI o de algunos príncipes del Renacimiento italiano"' (Estudios de historia del pensamiento español, Madrid, 1984, t. 3, p. 43).

51 “Después que te hubimos dado/la obediencia y que llegaste/-cuando menos lo esperaste-/al solio del principado,/desde la hora y el día/que hicimos de ti elección” (vv. 1363-1368); “Si fue tuya su elección,/¿por qué te quejas de Sexto?" (vv. 1397-1398); "Pero ya lo consiguió;/y conseguida la empresa,/lo que fue traición es gloria,/lo que fue engaño es grandeza;/y trocando los sucesos/la ignominia en excelencia,/pasa el nombre de traidor/a quien su obediencia niega" (vv. 1501-1508).

52 “Príncipe me hizo el Senado,/mas no sin dar causa yo/podrá deshacerme, no,/sin ser de traición notado; que el pueblo que reyes hace,/si deshacerlos quisiera,/no pudiera; y traición fuera/que de sediciones nace" (vv. 1431-1438).

53 “"pero una vez elegido,/mi lugar no he de perder;/soy cabeza, y he de ser/temido y obedecido" (vv. 1383-1386). 
sabilidad del acto y maniatándolo para cualquier forma de reivindicación o protesta.

La "irracionalidad" e incoherencia de los gabios consiste en pretender que el rey, a quien han elegido por cabeza, no cumpla luego con su función sirviéndose de los medios de que legítimamente dispone ${ }^{54}$; ello proporciona a Tarquino la ocasión de apelar a la tesis realista de la "cabeza" como natural e indispensable al "cuerpo" social y político, sin la cual el pueblo es sólo "una multitud acéfala" incapaz de existir como sociedad civil ${ }^{55}$.

En cuanto a Pericles, cabe aplicarle lo que dice Gracián de aquellos hombres que salen "del torno de su barro ya destinados para la servidumbre de unos espíritus serviles, sin género de brío en el corazón, inclinados al ajeno gusto, y ceder el proprio a cuantos hay" 56 . Sin embargo, en su vileza, tiene el buen tino de emplear los medios adecuados (la simulación, la adulación) para alcanzar su fin (la seguridad). Es él quien recuerda al espectador el fundamento de las relaciones que existen entre el que manda y los que obedecen. De su boca saldrá por única vez en la pieza la voz ley, para proclamar no sólo el fundamentojurídico bodiniano del absolutismo monárquico ( sólo al soberano corresponde "donner et casser la loi"), sino de la más pura arbitrariedad ("la loi c'est moi"): "tu voluntad [es] ley expresa"' (v. 1608). De ella sale igualmente la más reaccionaria concepción del poder, que Calderón perpetuara en La vida es sueño ("el rey es solo absoluto dueño"): "mi honor, mi vida y mi hacienda todo es tuyo" (v. 1518), recordando al tiempo que el honor, emanación de la potestad real, es el principio rector del orden social establecido ${ }^{57}$.

Julia muestra grandísima prudencia, pues afronta "racionalmente" su aspiración a ir a más no afrontándola, es decir, afrontándola como una imposibilidad y resolviendo el conflicto mediante la forma evasiva y elusiva del sueño ${ }^{58}$, que, como he dicho ya con respecto al desprecio del mundo y al conflicto realidad/aparien-

54 “'La república mejor,/para que ordenada esté,/es un cuerpo en quien se ve/la cabeza superior" (vv. 1375-1378).

55 Tal es la teoría de Jacobo I de Inglaterra; véase George H. Sabine, A history of political theory, H. Holt, New York, 1937, cap. 19.

${ }^{56}$ Gracián, op. cit., p. 52.

57 Véanse al respecto Maravall, Teatro y sociedad. .., p. 128, y AmÉRICO Castro, op. cit.

58 "Lucrecia: Dichosa tú que durmiendo/te olvidas de tus cuidados. Julia: Los que somos desgraciados/sólo vivimos durmiendo./Cuando duermo, a nadie ofendo"' (vv. 1818-1822). 
cia, no tiene aquí tampoco valor metafísico alguno.

Próxima a Pericles por su mediocridad y espíritu de servidumbre es la figura patética de Colatino, irracional en sus fines e incoherente en sus medios. Desde la óptica de la prudencia, es sin duda el personaje más despreciable: es el estulto bíblico, el necio $^{59}$. Necio le llama Bruto, de necio le acusa Lucrecia, como descargando en él aquel insistente Lucrecia-necia, de la que, al decir de Quevedo, "nadie ejemplo tome,/que escándalo siempre ha sido/del tiempo, y por consonante/de necia, está en los abismos" 60 . Colatino es la irracionalidad y la ceguera. Al contrario de Lucrecia, considera que las estrellas-son las responsables del obrar y del acaecer humano ${ }^{61}$. Lo tientan la superstición y la astrología. Crédulo y sospechoso, timorato, incierto en sus juicios, afronta la realidad no con base en el ver ( = juzgar, deducir, conocer), sino en la vana opinión (doxa), la duda y la sospecha. Incapaz de conocer y de conocerse, proyecta su mente deformante sobre el mundo. Su destino no es pisar el sur lo con pies de plomo, como es propio del varón sabio gracianesco, sino "pisar sombras"'62. Sus fines son vacuos y estériles: los dicta la vanidad, el

${ }^{59}$ Contra el refrán popular recordado por MACCURDY "no hay rico necio, ni pobre discreto" (op. cit., p. 115), el Barroco invierte los valores para sostener que las diferencias de estado no son nada con respecto a la igualdad del alma y del intelecto, y que los puestos altos resultan más bien desventajosos para la realización de sí mismo.

${ }^{60} B A E$, t. 69, p. 199 (citado por Gillet, op. cit., p. 124).

${ }^{61} \mathrm{El}$ abandono de las fuerzas de la voluntad a la fatalidad es propio tan sólo del necio, porque, como se ha visto, los demás personajes toman en sus manos el propio destino; lo que concuerda con la afirmación presente en $\mathrm{Del}$ rey abajo, ninguno: "no hay acción/alguna más vil que sujetarse a la Fortuna", destacada por Rodríguez-PuÉr TOLAS (op. cit., p. 361). El "nací a violencias inclinado", recordado por el mismo estudioso (ibid., p. 358) a raíz de nuestro Tarquino, encaja con el concepto renacentista del "inclinat aliquanter" sostenido por ejemplo, por Juan de Jandum, de la escuela averroísta de Padua, que no compromete para nada la libertad y los actos de la voluntad, como reconoce el propio PuÉrtolas unas líneas más abajo: "No hay que aceptar como inevitable el hado inhumano, la influencia de las fuerzas extrañas y misteriosas que oprimen al hombre. Hay, en fin, que querer ser' (ibid., p. 362). De distinta opinión a este respecto, KATLEEN GOULDSON: "Even more noticeable in Rojas' work is its fatalism. He appears to believe very strongly that every individual has a fixed destimy, determined by the influence of his own particular star. One's destiny is ordained prenatally. Every incident in one's life is therefore to be accepted with resignation" ("Religion and superstition in the plays of Rojas Zorrilla", in Spanish Golden Age poetry and drama, ed. E. Allison Peers, Phaeton Press, New York, 1974, p. 96).

${ }^{62}$ MacCurdy recuerda que esta bella expresión es un tópico barroco que 
más estúpido de los vicios, que tal es el significado de la vanitas en esta obra. Deseoso de ser el primero en todo, su sumisión y acatamiento a la monarquía son incondicionales y absolutos. Colatino es el "ejército bizarro", instrumento básico para el mantenimiento del poder, que el príncipe se asegura a fuerza de halagos y recompensas. Es el útil idiota que el monarca maneja y domina a su antojo para sus propios fines.

La ignorancia de Colatino no tiene límites: ignora la soberbia y ambición inherentes a la persona del príncipe, la insaciabilidad y prepotencia del poder, la naturaleza del amor y del honor; no distingue entre virtud interior (intención) y exterior (consecuencia), ni sabe que la primera es ineficaz en la defensa de la segunda. No ve que su doble objetivo - el honor y la vanagloria- encierra una contradicción. La vanidad le hace cometer la insensatez de exponer a la vista ajena un tesoro (honor/amor) que sólo es posible salvar guardando (ocultándolo) ${ }^{63}$. La comedia de repente subraya el carácter estulto de la competición alentada por Colatino, proporcionando, como observa justamente MacCurdy, el paralelo cómico a la competición "seria" (cabe añadir, no menos estúpida) de los soldados. De esta forma, Rojas desvirtúa el valor y significado de la competición presente en las demás Lucrecias, que reside en la necesidad de convalidar las ideas u opiniones adquiridas mediante la demostración experimental.

Ante la sospecha, que debiera ser "aviso" al prudente para predisponer los medios adecuados al nuevo fin propuesto, Colatino opone una resistencia desproporcionada e irrisoria. Frente a la "grandeza" de Tarquino, aparece como un enano. No hay obstáculo que aquél suprima con mayor facilidad y desenvoltura. Basta una pequeña operación táctica para alejar a Colatino del teatro donde va a perpetrarse la violación contra su esposa y contra él mismo. Ocurrido lo racionalmente necesario, no le queda siquiera el honor viril de vengar el ultraje, que le correspondería según el código del honor ${ }^{64}$, aunque la pieza prometa "para la segunda parte", la venganza del esposo y la reparación de la afrenta. Pero la ironía excluye ya de antemano que sea posible en Colati-

sirve "to arouse premonitions of death and to create the tragic mood" ( $o p$. cit., p. 138). No me parece que tenga aquí dicho significado, sino el que indico.

${ }^{63}$ Es significativo que Shakespeare, en su The rape of Lucrece, hable en idénticos términos.

${ }^{64}$ Véase AmÉrico CASTro, "Observaciones y notas a Rojas Zorrilla", en su edición de Cada cual lo que le toca, en Teatro antiguo español, Madrid, 1917, t. 2, pp. 184 ss. 
no tanta virilidad y arrojo. Es curioso que MacCurdy, que ha percibido una constante ironía en la obra (y que ni siquiera cabe ver en aquello de la "ironía de la suerte", porque no hay aquí suerte sino tan sólo inteligencia y voluntad, o incapacidad humana), no haya advertido la ironía que encierra este verso conclusivo: "Cese el llanto, empiece el ocio" (v. 2159). Si no se trata de una errata (ocio por odio), Rojas está aludiendo a las palabras de Bruto, quien, según la tradición, incita a los romanos a abandonar el ocio para pasar a la acción, es decir, al derrocamiento de la monarquía ilegítima ${ }^{65}$.

Con ese empiece en lugar del cese que cabría esperar en este momento, Rojas muestra de veras la ironía de una vicisitud cuyo resultado y objetivo finales son opuestos a los que ha imaginado la historia y la leyenda: exhortar a la impasibilidad social y política y a dejar que el mundo siga funcionando, con todas sus injusticias y crueldades, con la precisión de un mecanismo perfecto.

4. Fl mito o la historia de Lucrecia, en manos de Rojas, se articula en multitud de escenas de variada índole, que van del consabido "teatro en el teatro", a los frecuentes cambios de lugar y de escenografía y a las numerosas hipotiposis descriptivas, ricas en colorido y detalles, que "dibujan" ante el espectador escenas de grandiosa espectacularidad. Con ello, el auditorio capta al mismo tiempo el proceso mental verbalizado de los personajes en su triple fase de constatación y elaboración de los datos de la experiencia (yo veo que/yo deduzco que), creencia u opinión (las cosas son/la vida es) y deducción de comportamiento y prudencia (hay que/no hay que). Mediante la plasticidad escénica y el carácter no menos plástico de la alegoría y la sentencia en que se formula a menudo el pensamiento, Rojas se propone inculcar al espectador algunas "verdades" adquiridas, imponiéndolas menos por su fuerza demostrativa que por su impacto persuasivo. Dichas "verdades" se inscriben en el triple ámbito de lo individual, social y político.

En el orden individual, se afirma y enseña que: 1) el hombre está inscrito en un mecanismo cósmico, que incluye al hado, presidido por una idea o principio del Bien, que no interviene sino muy levemente (pre-ciencia divina/inclinación astral) en su ope-

${ }^{65}$ En el relato de la historia de Lucrecia de Tiro Livio, Ab Urbe condita, Paris, 1830, libro I, pp. 57-60, Bruto insta de continuo a los romanos a que abandonen las vanas discusiones y quejas y pasen a la acción viril: "castigator lacrimarum atque inertium querelarum". 
rar en el mundo; 2) el hombre es un ser libre que se realiza a sí mismo y es por tanto el único responsable de sus actos, en cuanto la "inclinación" que hace a los hombres diferentes debe considerarse parte de la propia e individual "circunstancia"; 3) el medio o terreno en que tiene lugar la acción humana (incluida la " inclinación") no es ni fatalidad ni obstáculo, sino ocasión con la que el hombre ha de contar y medirse, aprovechando la propicia y evitando o convirtiendo en útil para sus fines aquélla desfavorable; 4) los fines del hombre se inscriben en el doble ámbito de la conciencia y de la acción en el mundo (sociedad, Estado), y exigen normativas morales diferenciadas: mientras en el ámbito de la conciencia cuenta la irrelevante ética de la intención, sujeta al solo juicio divino, en la realización del hombre en el mundo vale la práctica de la conducta dictada por la circunstancia, que puede, y suele, no coincidir con los principios "cristianos" de la primera; 5) la dificultad de la vida no está en comportarse según conciencia, sino según prudencia, en cuanto en la acción exterior no es suficiente el sentido natural del bien o el acatamiento a las leyes divinas codificadas, sino una ciencia derivada de la experiencia, esto es, de la correcta evaluación de los datos que ella ofrece y de la eficaz elaboración mental-racional de los mismos; 6) lo "prudente" no es querer cambiar la circunstancia, sino amoldar el propio yo a la misma para sacar de ella el mayor provecho.

En su dimensión social, que es donde surgen los mayores problemas del hombre con su circunstancia, se sostiene y enseña que: 1) la circunstancia social está constituida por el conjunto de los hombres, cuya naturaleza es básicamente inmutable en el tiempo y en el espacio, aunque las combinaciones posibles de su comportamiento sean infinitas, por lo que el comportamiento humano es como una máquina dentro de la gran máquina del mundo; 2) la observación de dicho mecanismo muestra una naturaleza humana fundamentalmente malvada e hipócrita, que es la otra cara (no metafísica) de la metáfora o alegoría barroca del "teatro del mundo"; 3) existen unas estructuras inherentes a la sociedad que son inamovibles y sobre las cuales no cabe siquiera discutir: la familia, la ordenación estamental y el sistema social-político del honor; 4) siendo los hombres en su conjunto (el cuerpo social) y el sistema político-social la verdadera "circunstancia" del individuo, su táctica operativa debe consistir en mirar $(=$ conocer $)$ y guardarse ( = no dar ocasión a), esto es, evitar los daños que puedan provenir de dicha circunstancia.

En el orden político, las “enseñanzas" se refieren a la natu- 
raleza y configuración del Estado, a la legitimación de la monarquía absoluta y al ejercicio práctico del poder.

Con respecto a las primeras, se afirma que: 1) es necesario e ineludible para la existencia e interés de los individuos que el cuerpo social se constituya en Estado; 2) el Estado, como el cuerpo humano, es un organismo "natural", cuyos miembros carecen de vida propia, por lo que necesitan sujetarse a una cabeza que los coordine y "gobierne"'; 3) para dicho fin, la naturaleza (o la divinidad o las estrellas) ha predispuesto la existencia de un ser grande y excepcional, poseedor de grandes vicios y de grandes virtudes, que deben considerarse como las dos caras de una misma medalla; 4) dado que el Estado es impensable sin una cabeza de tales características, la forma de gobierno más conforme a naturaleza es la monarquía, una, absoluta e indivisible; 5) ese mecanismo (u organismo) que llamamos Estado exige la absoluta subordinación de los súbditos a un único “dueño", que lo es del poder supremo y también de la persona y haberes de sus súbditos; 6) si bien existe en los hombres un instintivo deseo de libertad y autonomía, ya que son incapaces de gobernarse por sí mis$\operatorname{mos}^{66}$, es razonable que repriman dicho deseo en beneficio propio; 7) la sujeción al poder es, pues, un mal menor necesario para la subsistencia y bienestar de los miembros que constituyen el cuerpo del Estado.

En cuanto a la legitimación de la monarquía absoluta se sostiene que: 1) sin perjuicio de su origen natural y/o divino, el fundamento de la monarquía, una, absoluta e indivisible, se halla en última instancia en la cesión voluntaria del poder que el pueblo ha realizado en favor del monarca en un momento u otro de su historia; 2) la ley de herencia asegura la continuidad de la voluntad (divina o humana) que se halla en los orígenes del poder ${ }^{67}$; 3) una vez expresa y hecha efectiva dicha "voluntad"' 68 , se esta-

66 Cf. SaAvedra Fajardo: "porque naturalmente se ama la libertad, y la parte del animal que está en el hombre es inobediente a la razón, y solamente se corrige con el temor. Por lo cual es conveniente que el príncipe dome a los súbditos como se doma un potro" ( $o p$. cit., p. 123). Significativamente VoLTAIRE, en pleno clima liberal, escribe: "le pur despotisme est le châtiment de la mauvaise conduite des hommes. Si une communauté d'hommes est maîtrisée par un seul ou par quelques-uns, c'est visiblement parce que'elle n'a eu ni le courage ni l'habilité de se gouverner elle-même" (Idées Republicaines, en Mélanges, Pléiade, Paris, 1961, p. 503).

${ }^{67} \mathrm{Ya}$ he dicho que la teoría del origen divino en realidad la sostiene Bruto; la ley de herencia es mencionada en los vv. 1 y 2 de la pieza.

${ }^{68}$ Cf. SaAvedra Fajardo: "la grandeza y poder del rey no está en sí mis- 
blece un pacto o contrato al que teóricamente están sujetas ambas partes y cuya violación representa, también por ambas partes, una traición; 4) cedido el poder, el pueblo no tiene derecho ni a intervenir en el gobierno, ni a oponer resistencia ni tanto menos a atentar contra la figura del monarca ${ }^{69}$, por lo que no existe más ley que la voluntad del soberano, como expresión de la voluntad del pueblo.

Por lo que se refiere al ejercicio del poder, se afirma y sostiene que: 1) objeto del poder es la conservación del Estado cuyos fines son los fines de la comunidad; 2) es legítimo que el monarca se sirva de todos los medios apropiados para el mantenimiento del poder, incluidos la simulación y el engaño y todos los recursos inherentes a la razón de Estado, aunque éstos contrasten con los principios de una ética interior (ley natural) o exterior (ley divina, derecho $)^{70}$; 3) entre los medios que aseguran la integridad y la salud de los miembros que forman el Estado, están la unidad territorial y la sujeción estamental ${ }^{71}$, por lo que es bueno que el monarca evite toda pretensión autonómica territorial o nobilaria; 4) aunque la conservación y buen mantenimiento del Estado excluyan consideraciones éticas ajenas a las exigencias peculiares del mismo, es oportuno y prudente que el príncipe se abstenga de tocar los bienes y las mujeres de sus súbditos, en cuanto los incita a la resistencia; 5) es también aconsejable que el monarca huya "de las ocasiones que pueden indignalle [al súbdito] haciendo nacer buena opinión de su gobierno" 72 ; 6) siendo el monarca hombre al fin y al cabo, está sujeto a las debilidades de todos los seres hu-

mo, sino en la voluntad de sus súbditos"' (op. cit., p. 118).

${ }^{69}$ Se trata del principio de la inviolabilidad sostenido por Hobbes y, significativamente, por Luis XIV: "Il faut assurément demeurer d'accord que, pour mauvais qui puisse être un prince, la révolte de ces sujets est toujours infiniment criminelle. Celui qui a donné des rois aux hommes a voulu qu'on les respectât comme ses lieutenants, se réservant à lui seul le droit d'examiner leur conduite. Sa volonté est que, quinconque est né sujet, obéisse sans discernement; et cette loi, si expresse et si universelle, n'est pas faite en faveur des princes seuls, mais est salutaire aux peuples mêmes auxquels elle est impossé, et qui ne la peuvent jamais violer sans s'exposer à des maux beaucoup plus terribles que ceux dont ils prétendent se garantir" (Mémoires de Louis XIV, Pion, Paris, 1928, pp. 254-255).

70 "Pues, en el puesto que ves, $/$ ino quieres que grave sea?/¡Ay del pueblo en quien se vea/la cabeza entre los pies!' (vv. 1407-1410).

71 "Pues, a pesar de nobles y villanos, /me veo por vos hoy rey de romanos"' (vv. 129-130).

72 SaAvedra Fajardo, op. cit., p. 122. 
manos, por lo que es preciso contar con eventuales abusos y tuertos que el súbdito prudente deberá esquivar con sagacidad y astucia, como parte de su circunstancia; 7) los errores, vicios y abusos del monarca están sólo sujetos al juicio divino y no comprometen ni invalidan la legitimación de su poder soberano.

De cuanto ha sido expuesto se infiere que el tema de Lucrecia y Tarquino de Rojas es la razón de Estado con el significado que ésta adquirió desde comienzos del siglo xviI: "la normativa racionalizada del obrar político y personal, motivada por la conveniencia y organizada por el cálculo'"73.

Como todo instrumento de propaganda, la obra no refleja la situación y opinión "reales" de la época, sino que revela en negativo las aspiraciones conscientes e inconscientes no menos reales de sus destinatarios. Para oponer resistencia a aspiraciones sociales y políticas que se infiltran así en la vida como en la pieza, Rojas trata de realzar la irracionalidad y el fracaso de toda forma de oposición y de dar justificación teórica al sistema social y político vigente. Para ello mezcla arbitrariamente la doctrina política maquiavélica con las doctrinas no menos maquiavélicas de quienes, en nombre de la Virtud y de la Ley divina, proclaman la necesidad de un príncipe que se atenga a la moral cristiana, y recoge indiscriminadamente las doctrinas realistas y antirrealistas sin llevar hasta sus últimas consecuencias lógicas ninguna de ellas, en cuanto ni se adentra en las cuestiones relativas al origen divino ni tampoco en los aspectos jurídicos del contrato o pacto, que llevarían necesariamente a los conceptos de soberanía popular y de rey-ciudadano por un lado, y a la justificación del tiranicidio, por el otro ${ }^{74}$.

Mostrando que con arreglo a la religión de la razón y de la prudencia y a la "fundamentada" concepción del príncipe, Tar-

${ }^{73}$ Maravall, Estudios de historia del pensamiento español, p. 239.

74 Virgilio Malvezzi sostiene en más de una ocasión la legitimidad del tiranicidio, aunque justo en Tarquino il Superbo acepte la tiranía con resignada fatalidad, como algo inherente a la naturaleza. En cualquier caso, Malvezzi no siente ninguna simpatía por el sacrificio de Lucrecia, como lo demuestran las palabras citadas por el mismo MACCuRdy (op. cit., p. 326) y este párrafo: "Se costoro [los que se suicidan para evitar la tiranía] non potevano, o non volevano vivere, perché non tentavano di far morire il tiranno? Quel pericolo che avrebbero corso sarebbe stato quello stesso che non sapevano fuggire o che bramavano d'incontrare. Il premio che si offeriva loro era speranza di vivere con onore o per lo meno sicurezza di non morire senza gloria" (Tarquino il Superbo, Bologna, 1632, p. 88). Por ese mismo motivo, como recuerda GILLET (op. cit., p. 133), Cervantes trata con desdén el tema en el Quijote (I, 34). 
quino no sólo es el menos culpable, sino que, grande en su potencia y en su caída, se yergue por encima de la despreciable mediocridad de sus súbditos; que, por consiguiente, como sostiene Malvezzi $^{75}$, es soportable en cuanto, si no se le puede reconocer como buena persona, por lo menos se le puede reconocer como un gran príncipe; admitiendo, como sostiene Saavedra Fajardo, que "ninguna prudencia puede acertar en todo"'76, que Tarquino ha pecado como hombre y no como príncipe, y que como tal está sujeto tan sólo a la justicia divina. Ignorando el fundamento jurídico del poder y haciendo hincapié en las razones y justificaciones prácticas de la razón de Estado; demostrando la validez e indiscutibilidad del sistema nobiliario del honor como fundamento de la majestad absoluta del soberano; reduciendo la figura de Bruto a mera comparsa y resolviendo la venganza de Lucrecia sobre ella misma sin que el puñal del crimen pase a las manos revolucionarias y colectivas de Bruto para la destrucción de la tiranía; dejando para una supuesta y no existente segunda parte una venganza que deja incólume la figura del monarca; abogando por la locura disimuladora que espera indefinidamente la ocasión propicia para derribar al tirano y por el prudente acomodo al sistema, en vez de proclamar el derecho a la oposición y a la resistencia; insistiendo en que sólo el individuo, y no la sociedad, es responsable de sus males y que la felicidad humana depende exclusivamente de la perfecta adecuación de los medios a fines que establece e impone el sistema; haciendo que ningún personaje imagine siquiera una solución que esté fuera de los esquemas que les imponen las convenciones y constricciones sociales ${ }^{77}$; insistiendo en la visión pesimista de la naturaleza y condición humanas, ante la cual todo ideal o utopía de perfección y progreso es vano, Rojas convierte el mito revolucionario por excelencia de la tradición europea en panfleto del más reaccionario conservadurismo moral, social y político.

Reducida la alegoría a mero conflicto y drama de honor y sustituido el deseo de fama implícito en el gesto suicida de Lucrecia por el de buena reputación, el sacrificio de la heroína pierde el

75 ' ' $\mathrm{E}$ ' necessario che i sudditi, acciocché sopportino pazientemente il tiranno, se non lo conoscono per un buon principe, che lo confessino almeno per un gran principe"' (Tarquino il Superbo, p. 51).

76 SaAvedra Fajardo, op. cit., p. 37.

77 No creo, como sostiene Caldera (op. cit., pp. 43 ss.), que la renuncia tenga el significado existencial que él le atribuye, sino una función social y política muy clara. 
valor simbólico de regeneración histórica ${ }^{78}$ para ofrecerse como un doble caso de ejemplaridad negativa. Por un lado es una pequeña e inofensiva lección de Príncipes, que recuerda que la prudencia y la violencia deben estar unidas en el ejercicio del poder, y que la potencia del Estado corre graves peligros cuando se infringen indiscriminada e innecesariamente los valores de la moral y del derecho. Por el otro, es un "aviso" que se suma, para el espectador, a los tantos que vienen del mundo y de la historia, para escarmentar en cabeza ajena y aprender a afinar la propia prudencia y la propia adecuación de los medios a los fines que la sociedad impone, porque "los errores de los que ya fueron advierten a los que son" 79 .

Loreto Busquets

Università Cattolica del Sacro Cuore, Milano

\footnotetext{
${ }^{78}$ Sobre los conceptos de alegoría, fama y regeneración histórica, véase mi La tragedia neoclásica española. . . La divergencia fundamental entre la pieza de Rojas Zorrilla y la obra de Malvezzi reside en el hecho de que para éste el suicidio, desde el punto de vista político, es injustificable y, en cualquier caso, inútil e innecesario. Lo que pasa es que Rojas ha deslizado el tema del terreno político al social (el honor), y en esta óptica el suicidio se justifica como resultado necesario de la afrenta. No creo pues que la "necedad" de Lucrecia consista en el suicidio (como sostiene Gillet en general para el Barroco), sino en los errores que Lucrecia ha cometido y con los que indirectamente ha atraído la desdicha sobre sí misma; véase Gillet, op. cit., pp. 134-135. Así pues, en Rojas, el sacrificio de Lucrecia es tomado en serio, como en otros casos recordados por CALDERA, op. cit., p. 57.

${ }^{79}$ SaAvedra Fajardo, op. cit., p. 117. La tesis maquiavélica de la validez y utilidad de la imitación de los ejemplos de la Historia, es sostenida también por Virgilio MalvezzI, por lo menos en un primer tiempo: "rendere più capaci gli uomini che gli effetti passati non erano fortuiti e fare che siano atti a prevedere quelli per l'avvenire da simili cagioni possono essere prodotte" (Discorsi sopra Cornelio Tacito, p. 3).
} 